\title{
国家药监局启动中国药品监管科学行动计划 国家药品监督管理局2019年4月30日发布
}

\author{
细胞和基因治疗产品、药械组合产品、人工智能医疗器械、中药安全评价研究等首批立项
}

为全面贯彻落实习近平总书记有关药品安全 “四个最严” 要求, 围绕 “创新、质量、效率、体系、能力” 主题, 推动监管理念制度机制创新, 加快推进我国从制药大国向制药强国迈进, 国家药品监督管理局今日发 布通知, 决定开展药品、医疗器械、化妆品监管科学研究, 启动实施中国药品监管科学行动计划, 并确定首 批九个重点研究项目。

通知指出, 立足我国药品监管工作实际, 围绕药品审评审批制度改革创新, 密切跟踪国际监管发展前沿, 拟通过监管工具、标准、方法等系列创新, 经过 3-5 年的努力, 制定一批监管政策、审评技术规范指南、检 查检验评价技术、技术标准等, 有效解决影响和制约药品创新、质量、效率的突出性问题, 加快实现药品治 理体系和治理能力现代化。

监管科学行动计划明确了 3 项重点任务: 建设 3-5 家药品监管科学研究基地; 启动一批监管科学重点项 目; 推出一批药品审评与监管新制度、新工具、新标准、新方法。

监管科学重点项目将分批分期推出, 实现关键领域突破。项目将聚焦细胞和基因治疗、再生医学、药械 组合等前沿性、交叉性产品, 由相关业务司局牵头, 会同有关直属单位和部分省局, 联合高校、科研机构、 行业协会等开展创新性研究。

首批启动的行动计划项目共有九项，分别是细胞和基因治疗产品技术评价与监管体系研究、纳米类药物 安全性评价及质量控制研究、以中医临床为导向的中药安全评价研究、上市后药品的安全性监测和评价方法 研究、药械组合产品技术评价研究、人工智能医疗器械安全有效性评价研究、医疗器械新材料监管科学研究、 真实世界数据用于医疗器械临床评价的方法学研究、化妆品安全性评价方法研究。

药品监管科学研究基地将依托国内知名高等院校、科研机构, 围绕药品全生命周期, 开展监管科学重点 项目研究, 开发系列新工具、新标准和新方法, 夯实我国药品监管科学基础, 助力药品监管科学可持续发展。 同时，深入开展药品监管科学基础理论研究，推进监管科学学科建设，培养监管科学领军人才。 